\title{
Mudanças do Uso e de Cobertura da Terra na Região Semiárida de Sergipe
}

\author{
Márcia Rodrigues de Moura Fernandes ${ }^{1}$, \\ Eraldo Aparecido Trondoli Matricardi ${ }^{1}$, André Quintão de Almeida ${ }^{2}$, \\ Milton Marques Fernandes ${ }^{3}$
}

\begin{abstract}
${ }^{1}$ Departamento de Engenharia Florestal, Universidade de Brasília - UnB, Brasília/DF, Brasil ${ }^{2}$ Departamento de Engenharia Agrícola - DEA, Universidade Federal de Sergipe - UFS, São Cristóvão/SE, Brasil

${ }^{3}$ Departamento de Ciências Florestais, Universidade Federal de Sergipe - UFS, São Cristóvão/SE, Brasil
\end{abstract}

\section{RESUMO}

No presente estudo, foi realizada uma análise temporal do uso e da cobertura da terra na região semiárida de Sergipe. Para tanto, foram utilizadas imagens dos satélites Landsat-5 TM e Landsat-8 OLI, adquiridas nos anos de 1992, 2003 e 2013. Utilizou-se o algoritmo da máxima verossimilhança, que possibilitou a classificação de seis classes de uso e de cobertura da terra. Para validação dos dados, foi usada uma imagem Spot-5, de alta resolução espacial, como referência de dados para as classes de uso e de cobertura escolhidas. Os resultados indicam um aumento de mais de $26 \%$ do desmatamento da vegetação nativa na área de estudo. A vegetação da Caatinga foi a mais impactada, a maioria convertida em novas pastagens. Além disso, observou-se que o aumento do desmatamento na área de estudo ocasionou também uma redução da Caatinga preservada e da regeneração florestal.

Palavras-chave: caatinga, desmatamento, geoprocessamento, sensoriamento remoto.

\section{Land Use and Land Cover Changes in the Sergipe Semiarid Region}

\begin{abstract}
This study performed a temporal analysis of the land use and coverage in the semiarid region of Sergipe. We used Landsat-5 TM and Landsat-8 OLI satellite images acquired in 1992, 2003 and 2013. The maximum likelihood algorithm was used to detect six classes of land use and land coverage. We used a high spatial resolution Spot-5 scene as reference data to validate the assigned land use and coverage classification. Our results indicate that deforestation of native vegetation increased approximately $26 \%$ in the study area. The Caatinga vegetation was the most impacted, mostly converted to pastureland. In addition, it was observed that the deforestation increase in the study area negatively affected the preserved Caatinga secondary regrowth.
\end{abstract}

Keywords: caatinga, deforestation, geoprocessing, remote sensing. 


\section{INTRODUÇÃO}

A Caatinga, bioma exclusivamente brasileiro, ocupa uma área de aproximadamente $844.453 \mathrm{~km}^{2}$, o equivalente a 10\% do território nacional (SFB, 2013). Originalmente, ela recobria quase todo o semiárido nordestino (IBGE, 2010) e, no Estado de Sergipe, correspondia no ano de 2007 a $26 \%$ do estado (PROBIO, 2007).

A região semiárida, ocupada predominantemente pelo bioma Caatinga, vem sendo exposta a um intenso processo de degradação pelo avanço da pecuária, cujo início se deu ainda no século XVII (Nogueira \& Simões, 2009). A situação se agravou ao longo dos anos pelo uso incorreto das suas terras, submetidas à exploração predatória, desmatamentos e queimadas (Brasileiro, 2009).

Em Sergipe, a região semiárida é marcada pela degradação da cobertura florestal e é inevitável deixar de relacioná-la com os modos de produção predominante. Desse modo, destacam-se: (i) a disseminação de práticas agrícolas inadequadas; (ii) o pastoreio excessivo; (iii) o desmatamento; (iv) a destruição de áreas com vegetação nativa; (v) o desaparecimento de muitas espécies animais e vegetais, colocando-se em questão a própria capacidade de uso da terra e dos recursos para a manutenção das atividades produtivas e para a garantia de serviços ambientais (Sergipe, 2014).

Os estudos da cobertura florestal ou da cobertura e do uso da terra, sua dinâmica e seus impactos cresceram com os trabalhos sobre as mudanças ambientais na última década, os quais vêm sendo desenvolvidos no semiárido da região Nordeste do Brasil (Silva et al., 2011; Cunha et al., 2012; Silva et al., 2013; Silva et al., 2014). Araújo et al. (2012), estudando espacialmente a cobertura florestal da área de preservação permanente (APP) do Rio Mossoró, no Rio Grande do Norte, conseguiram constatar, em toda a área, a quase inexistência da vegetação nativa. Silva et al. (2009), analisando a dinâmica espaço-temporal da vegetação no semiárido de Pernambuco, verificaram que a vegetação da Caatinga da região diminuiu, mostrando que as áreas analisadas encontram-se em processo de perda da vegetação, o que pode levar ao processo de desertificação.

Apesar disso, ainda há escassez de estudos sobre as alterações no uso e na cobertura da terra na região semiárida de Sergipe. Dessa forma, é de suma importância estudos voltados para essa região buscando avaliar a situação da cobertura vegetal, de forma a produzir base científica para subsidiar o entendimento dos processos de desmatamento e a definição de políticas públicas e de diretrizes para o uso sustentável do bioma Caatinga nesse Estado. Assim, a presente pesquisa buscou realizar uma análise temporal do uso e da cobertura da terra na região semiárida de Sergipe, a partir de imagens Landsat-5 TM e Landsat-8 OLI, dos anos de 1992, 2003 e 2013.

\section{MATERIAL E MÉTODOS}

\subsection{Localização e caracterização da área de estudo}

A área de estudo compreende toda a região semiárida (Figura 1) do Estado de Sergipe, ou seja, aproximadamente $11.177 \mathrm{Km}^{2}$ (Sergipe, 2014), localizada nas coordenadas $9^{\circ} 31^{\prime} 11^{\prime \prime}$ S e $11^{\circ} 18^{\prime} 36^{\prime \prime}$, e $36^{\circ} 39^{\prime} 10^{\prime \prime} \mathrm{W}$ e $38^{\circ} 13^{\prime} 13^{\prime \prime} \mathrm{W}$. A altitude varia entre 25 e $750 \mathrm{~m}$, fazendo fronteira com os Estados da Bahia e de Alagoas.

O clima na região é semiárido do tipo "BSh" segundo a classificação de Köppen, com baixa incidência pluviométrica, que varia entre 250 e $900 \mathrm{~mm} / \mathrm{ano}^{-1}$ (Alves, 2007) e com duas estações distintas durante o ano: a estação chuvosa, ou inverno, que dura de três a cinco meses ( $\sim$ maio a setembro), apresentando chuvas irregulares e de pouca duração; e a estação seca, ou verão, que pode durar de sete a nove meses ( outubro a abril) e quase não apresenta chuva (Maia, 2004). As temperaturas médias anuais são relativamente elevadas, entre 26 a $29^{\circ} \mathrm{C}$ (Alves, 2007).

\subsection{Base de dados}

Foram adquiridas imagens do satélite Landsat-5 sensor TM (Thematic Mapper) dos anos de 1992 e 2003 e do satélite Landsat-8 sensor OLI (Operational Land Imager) do ano de 2013, cujas cenas são identificadas pela órbita (Path) 215 e pontos (Row) 67 e 68, datadas de maio, janeiro e abril, respectivamente, com resolução espacial de $30 \mathrm{~m}$, além de uma imagem Spot- 5 do ano de 2004. Os dados utilizados neste trabalho foram cedidos pela Superintendência de Recursos Hídricos (SRH) do Estado de Sergipe e do sítio do Serviço Geológico Americano (USGS) (Tabela 1). As imagens de satélite foram selecionadas em função da menor presença de 
nuvens, sendo aceito, segundo Prado et al. (2007), 35\% ou menos da imagem coberta por nuvens.

\subsection{Processamento das imagens de satélite}

As imagens Landsat foram processadas no software Erdas Imagine ${ }^{\circledast} 11$. As observações visuais preliminares foram feitas sobre as imagens na composição colorida 5(R)4(G)3(B) para as imagens do Landsat-5 e na 6(R)5(G)4(B) para a imagem do Landsat-8. As imagens foram georreferenciadas por meio do sistema de coordenadas UTM, Zona 24 Sul, Datum WGS-84. Para o registro das imagens Landsat, usou-se uma imagem Spot-5, com resolução espacial de $5 \mathrm{~m}$, do ano 2004, como referência geométrica. Aplicou-se uma transformação polinomial de primeiro grau, gerando-se erros médios quadráticos (RMS) inferiores a 1 pixel da imagem Landsat. Em seguida, as imagens foram submetidas ao tratamento de realce de contrastes e se fez a equalização para melhor identificação e agrupamento dos aspectos referentes ao uso e à cobertura da terra.

As imagens foram submetidas à classificação supervisionada por máxima verossimilhança. A classificação automática foi realizada no software Erdas, ferramenta Maximum Likelihood, na qual foi possível classificar seis classes: Caatinga, capoeira (regeneração secundária), cultivo agrícola, pastagem, solo exposto e corpos d'água.
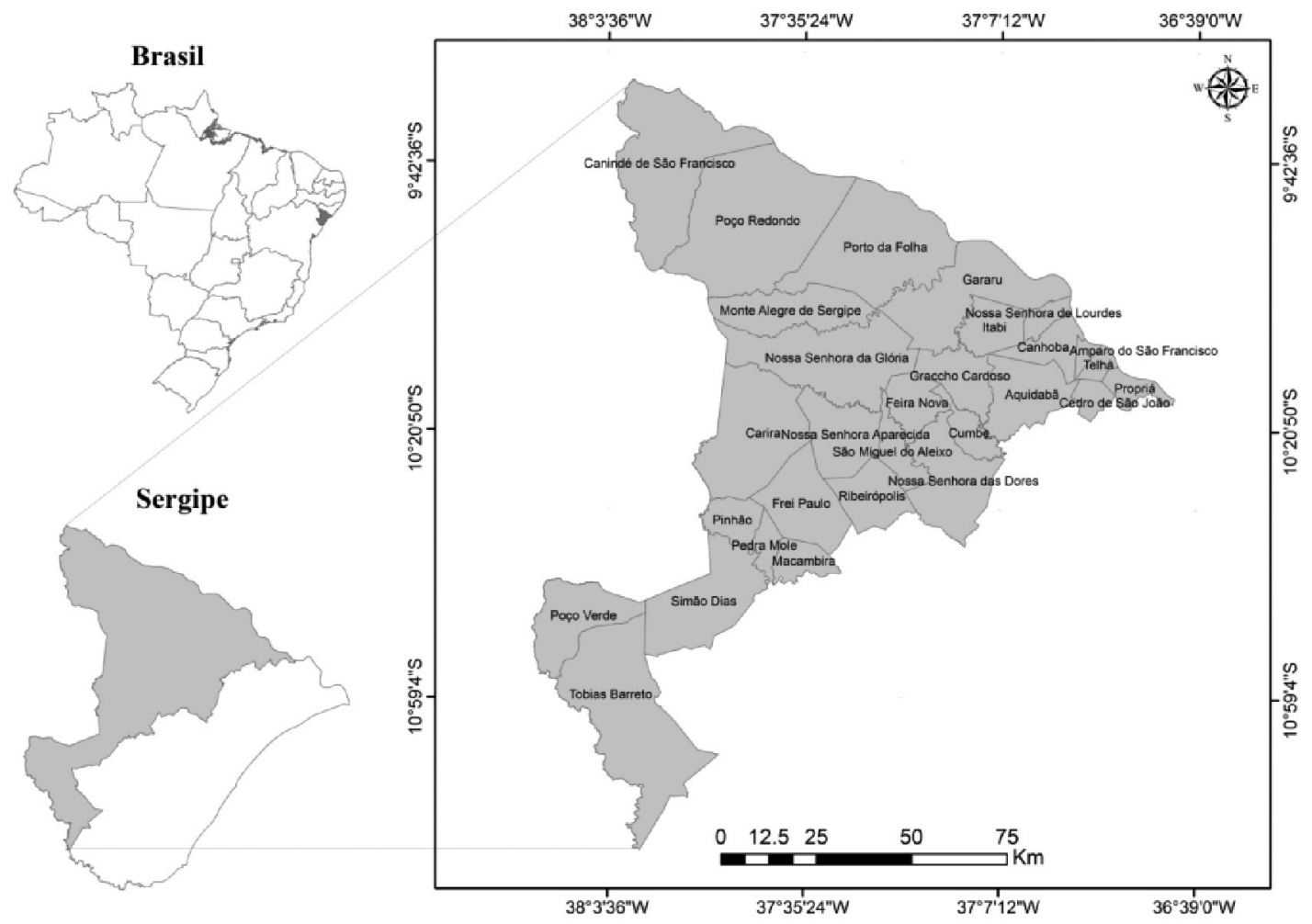

Figura 1. Localização da área de estudo.

Figure 1. Location of the study area.

Tabela 1. Fonte de dados utilizados no estudo.

Table 1. Source of data used in the study.

\begin{tabular}{ccccc}
\hline Fonte & Tipo de dado & Dado & Data/Período & Escala/resolução \\
\hline SRH & Vetorial & Região semiárida & 2005 & $1: 250.000$ \\
\hline SRH & Vetorial & Municípios & 2010 & $1: 250.000$ \\
\hline SRH & Raster & Imagem SPOT-5 & 2004 & $5 \times 5 \mathrm{~m}$ \\
\hline USGS & Raster & Imagem Landsat-5 & 1992,2003 & $30 \mathrm{~m}$ \\
\hline USGS & Raster & Imagem Landsat-8 & 2013 & $30 \mathrm{~m}$ \\
\hline
\end{tabular}


Foram definidas e coletadas 60 amostras de treinamento para cada classe de uso e de cobertura da terra presente nas imagens, utilizando-se a ferramenta Signature Editor. Para definição das classes mapeadas e as áreas utilizadas nas amostras de treinamento, teve-se um conhecimento prévio da área representada da imagem, feito por meio de visitas a campo e da utilização da imagem Spot-5.

Após a classificação, na fase de pós-processamento, aplicou-se filtro Majority $7 \times 7$ para eliminar grupo de células com áreas dispersas na imagem classificada, visando melhorar a qualidade visual da imagem final e eliminando pequenas células ou pixels isolados, definidos por Lillesand \& Kiefer (1994) como aspecto ruidoso.

\subsection{Avaliação da acurácia da classificação do uso e da cobertura da terra}

Com a finalidade de avaliar a qualidade da classificação do mapa gerado, foi realizada uma avaliação da acurácia com a utilização da matriz de confusão, cuja geração se deu por meio do programa Erdas a partir de comparação de classificações das imagens de alta resolução espacial do satélite Spot-5, adquiridas em 2004, e do Landsat-5 TM, adquiridas em 2003. A classificação feita a partir da imagem Spot foi utilizada como referência de campo. A escolha do ano de 2003 (Landsat) e 2004 (Spot) para comparação e cálculo da matriz de confusão foi devido à maior proximidade temporal e à disponibilidade de imagens para a área de estudo. Dessa forma, foram feitas a classificação na imagem Landsat-5 do ano de 2003 e a aleatoriedade de 200 pontos nessa imagem, com o auxílio da ferramenta Add Randon Points. Cada ponto aleatorizado foi checado visualmente por um fotointérprete com conhecimento da área de estudo, possibilitando obter os dados para a matriz de erros, o que permitiu o cálculo dos índices Kappa (Landis \& Koch, 1977) e a exatidão global pela ferramenta Accuracy Assessment. Como referência para os resultados obtidos na matriz de confusão, foi utilizada a classificação sugerida por Landis \& Koch (1977), apresentada na Tabela 2.

\subsection{Avaliação da dinâmica do uso e da cobertura da terra}

Para cada ano da pesquisa (1992, 2003 e 2013), as imagens classificadas foram processadas no software ArcGIS $^{\circledast} 10.2$ e convertidas para o formato vetorial.
Tabela 2. Classificação baseada na estatística Kappa.

Table 2. Kappa statistics based on classification.

\begin{tabular}{cc} 
Coeficiente Kappa & Qualidade da classificação \\
$<0$ & Péssima \\
$0-0,2$ & Ruim \\
$0,21-0,4$ & Razoável \\
$0,41-0,6$ & Boa \\
$0,61-0,8$ & Muito boa \\
$0,81-1,0$ & Excelente \\
\hline
\end{tabular}

Fonte: Landis \& Koch (1977).

Os mapas vetoriais foram editados como mapa temático para quantificação das classes temáticas (Caatinga, capoeira, cultivo agrícola, pastagem, solo exposto e corpos d'água) utilizando-se a calculadora de atributos do referido ArcGIS.

A análise da dinâmica temporal da cobertura florestal remanescente foi realizada a partir dos mapas de uso da terra gerados. Foram estimadas as classes de florestas em três períodos: (i) 1992 a 2003, (ii) 2003 a 2013 e (iii) 1992 a 2013.

Os dados da dinâmica florestal foram organizados sob a análise das áreas obtidas para cada dois períodos sequenciais, nos quais se avaliou a Caatinga preservada, a regeneração florestal e o desmatamento. Esses dados foram gerados por meio do programa ArcGIS, com o auxílio da ferramenta intersect a partir do cruzamento dos mapas de classificação de uso e de cobertura da terra. Nesse caso, fez-se o cruzamento de três períodos.

Os primeiros dois períodos de análise da dinâmica da cobertura florestal (1992-2003 e 2003-2013) foram realizados para o melhor entendimento das mudanças do uso e da cobertura da terra ocorrida em períodos distintos. Por fim, o período de análise de 1992-2013 serviu para quantificar as mudanças em todo o período.

Foram consideradas como Caatinga preservada as áreas que, no período inicial e posterior da análise, apresentavam-se e mantiveram-se coberta por vegetação de Caatinga. Para avaliar o desmatamento, foram utilizadas as áreas que, no início do período, apresentavam Caatinga e, ao final, eram compostas por outras classes (capoeira, cultivo agrícola, pastagem, solo exposto e corpos d'água). Por fim, ao contrário disso, quando outras classes identificadas na data inicial eram convertidas à Caatinga na data final, considerou-se como regeneração florestal. 


\section{RESULTADOS E DISCUSSÃO}

$\mathrm{Na}$ avaliação do desempenho da classificação supervisionada do uso e da cobertura da terra para o ano de 2003, obteve-se um índice de concordância Kappa de 0,60. Segundo Landis \& Koch (1977), tais resultados indicam uma boa performance do classificador. Já a exatidão global da classificação do uso da terra para 2003 foi de $82,5 \%$, também considerada muito boa.

A Tabela 3 apresenta os resultados encontrados nas classificações do uso e da cobertura da terra dos anos avaliados nas classes mapeadas. Tais resultados refletem o aumento de áreas de pastagem e de áreas de cultivos agrícolas, devido ao incentivo fiscal e à modernização da produção, atrelados à diminuição das classes Caatinga e capoeira.

As mudanças mais substanciais observadas correspondem às áreas de Caatinga, com diminuição de $22,2 \%$, de capoeira, com redução de $5,9 \%$, e de corpos d'água, com diminuição de 0,2\% entre 1992 e 2013. Silva et al. (2013), avaliando a dinâmica de uso e de cobertura da terra, no município de Floresta, em uma região semiárida de Pernambuco, também observaram que a cobertura florestal nativa recuou $14,8 \%$, em um período de 21 anos (1987-2008).

Observou-se também o aumento das áreas de pastagem (23,3\%), de cultivos agrícolas $(1,7 \%)$ e solo exposto $(3,2 \%)$ em todo o período de análise deste estudo. $\mathrm{O}$ aumento das áreas de pastagem na região semiárida de Sergipe está relacionado à tendência de expansão da pecuária em Sergipe, pois a maior parte (68\%) das propriedades rurais está voltada à formação de pastagem e produção pecuária (Sergipe, 2014).

No mapeamento realizado para o ano de 1992, aproximadamente a metade $(48,9 \%)$ da área da região de estudo estava coberta por pastagem e 37,2\% estavam cobertos por vegetação de Caatinga. Em 2003, os resultados deste estudo apontam um aumento na área de pastagem (55\%) e cultivo agrícola $(1,3 \%)$ e uma redução na área de Caatinga (33,6\%) e capoeira $(4,3 \%)$. Em 2013, as áreas ocupadas com Pastagens aumentaram $17,2 \%$ quando comparada a 2003, tendência inversa ocorrida nas áreas de Caatinga, que diminuíram 18,6\% no mesmo período.

Sousa et al. (2008), estudando a vegetação semiárida do município de Boa Vista, na Paraíba, observaram que a cobertura florestal sofreu redução também ao longo dos anos estudados, sendo relacionados com o elevado uso das terras para pecuária extensiva e pela falta de renda da população rural, a qual, por falta de melhores alternativas energéticas, utiliza a vegetação na forma de lenha.

Barbosa et al. (2009), estudando a evolução da cobertura vegetal e o uso agrícola do solo na região semiárida no município de Lagoa Seca, na Paraíba, observaram que o significativo aumento de áreas exploradas com a pecuária na região pode ser visto também sob dois aspectos: substituição do tipo de exploração, por causa da resposta economicamente positiva nas áreas em que antes se cultivavam culturas comerciais, como a fruticultura e olericultura, e substituição da vegetação nativa por pastagem, devido à possibilidade de um aproveitamento econômico, semelhante ao observado na região semiárida de Sergipe.

A região semiárida de Sergipe, historicamente, apresentava uma estrutura fundiária em pequenas e médias propriedades, com o cultivo de subsistência do milho, da mandioca e a criação de gado para consumo doméstico. No entanto, a região semiárida de Sergipe nos últimos anos vem apresentando um

Tabela 3. Quantificação do uso e cobertura da terra e suas respectivas porcentagens entre os anos de 1992,2003 e 2013 na região semiárida de Sergipe.

Table 3. Land use/land cover quantification and their respective percentages in the years 1992, 2003 and 2013 in the semiarid region of Sergipe.

\begin{tabular}{|c|c|c|c|c|c|c|}
\hline Usos & $1992\left(\mathrm{Km}^{2}\right)$ & $\%$ & $2003\left(\mathrm{Km}^{2}\right)$ & $\%$ & $2013\left(\mathrm{Km}^{2}\right)$ & $\%$ \\
\hline Caatinga & $3.985,9$ & 37,2 & $3.605,3$ & 33,6 & $1.610,3$ & 15,0 \\
\hline Capoeira & 866,7 & 8,1 & 457,5 & 4,3 & 239,2 & 2,2 \\
\hline Cultivo agrícola & 111,5 & 1,0 & 141,2 & 1,3 & 290,4 & 2,7 \\
\hline Pastagem & $5.244,2$ & 48,9 & $5.900,1$ & 55,0 & $7.746,1$ & 72,2 \\
\hline Solo exposto & 368,0 & 3,4 & 491,9 & 4,6 & 712,0 & 6,6 \\
\hline Corpos d'água & 152,9 & 1,4 & 133,2 & 1,2 & 131,2 & 1,3 \\
\hline Total & $10.729,2$ & 100 & $10.729,2$ & 100 & $10.729,2$ & 100 \\
\hline
\end{tabular}


crescente aumento da sua produção leiteira, o que vem pressionando a conversão de Caatinga em pastagens. Segundo Oliveira et al. (2013), o Estado de Sergipe obteve uma produção de 296,6 milhões de litros de leite, ocupando $17^{\mathrm{a}}$ posição como maior Estado produtor, representando $1 \%$ da produção leiteira nacional.

Com relação ao aumento de 3,4\%, 4,6\% e 6,6\% da classe solo exposto nos anos de 1992, 2003 e 2013, respectivamente, observou-se que a maior parte dessas áreas foram ocupadas por pastagens e, posteriormente, abandonadas. Tal fato contribui com o aumento das áreas degradadas e susceptíveis à erosão dos solos. Resultado semelhante foi encontrado por Feitosa et al. (2010), que trabalharam com a avaliação da degradação na cobertura vegetal no semiárido da Paraíba e concluíram que o acréscimo das áreas de solo exposto foi em decorrência da perda da cobertura florestal, o que demonstra o aumento das vulnerabilidades na expansão dessas áreas de grave a muito grave e reflete a importância em intervir nesse processo acelerado de devastação da Caatinga, o qual se dá pelo uso irracional desse recurso natural.

As áreas de cultivos agrícolas nos anos entre 1992 a 2013 obtiveram, na área de estudo, um aumento de $1,8 \%$, o qual parece estar relacionado à disponibilidade de 30.000 ha potencialmente irrigáveis priorizadas pelo governo do Estado de Sergipe, lançadas como um esforço sistemático para aproveitamento dos recursos hídricos desse Estado. Posteriormente, foram construídos e implantados nesse período pela Companhia de Desenvolvimento de Recursos Hídricos e Irrigação de Sergipe (CODEVASF) seis perímetros irrigados. Além disso, novos investimentos voltados para o fortalecimento da infraestrutura de irrigação deverão contribuir para o desenvolvimento da região na produção de alimentos, na criação de empregos e no aumento da renda regional (CODEVASF, 2010).

As áreas ocupadas por corpos d'água no ano de 1992, 2003 e 2013 apresentaram valores estáveis de $1,4 \%, 1,2 \%$ e $1,3 \%$. Tais resultados revelam uma queda relativamente pequena de $0,2 \%$ entre 1992 e 2013, o que equivale a uma redução de $21,7 \mathrm{~km}^{2}$ de toda a área coberta por corpos de água na área de estudo. Essa classe pode variar de acordo com o volume de chuvas ocorridas a cada ano e, eventualmente, com novos represamentos de rios.

Observou-se que houve uma grande conversão de áreas de Caatinga em pastagem de 1992, 2003 e desta em regeneração secundária de 2003, 2013 na região do Alto Sertão (Figuras 2a, 3a e 4a). Conforme visitas em

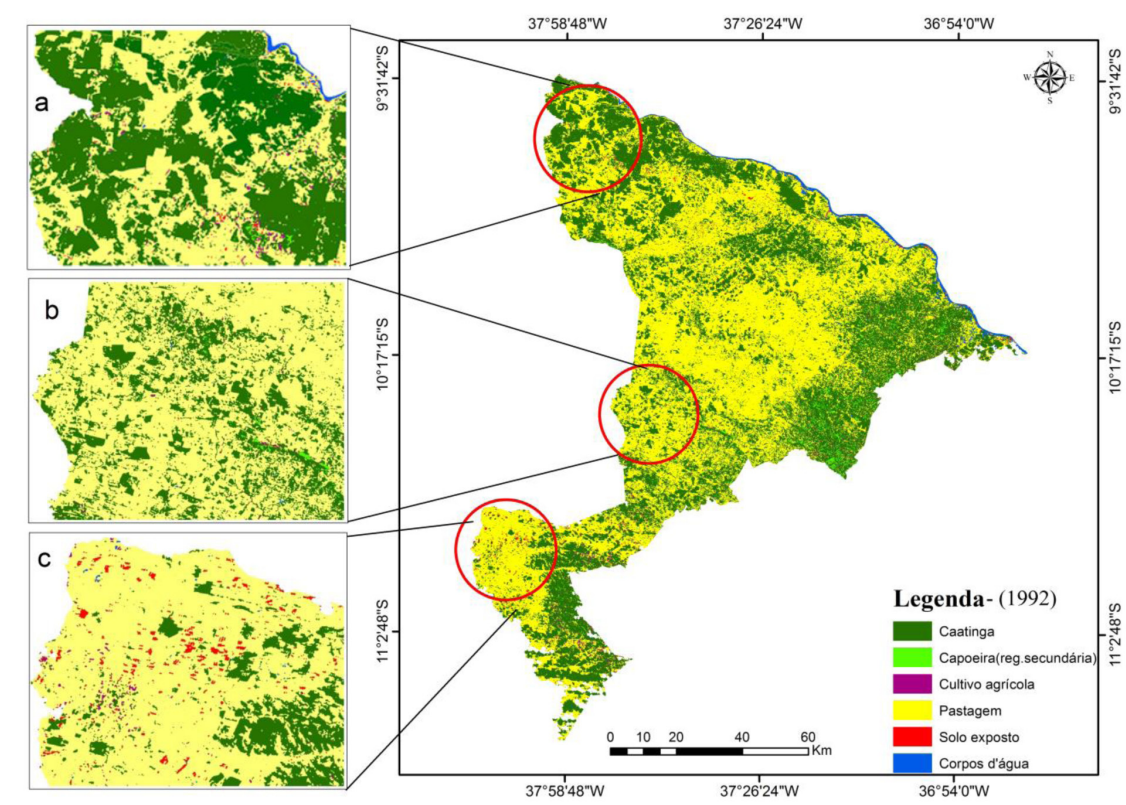

Figura 2. Mapa de uso e cobertura da terra da região semiárida de Sergipe no ano 1992; em em destaque, as regiões do Alto Sertão (a), Agreste Central (b) e Centro-Sul (c).

Figure 2. Land use/land cover map in the semiarid region of Sergipe, the year 1992 and featured in the Hinterland (a) Central Wasteland (b) and Central South (c). 


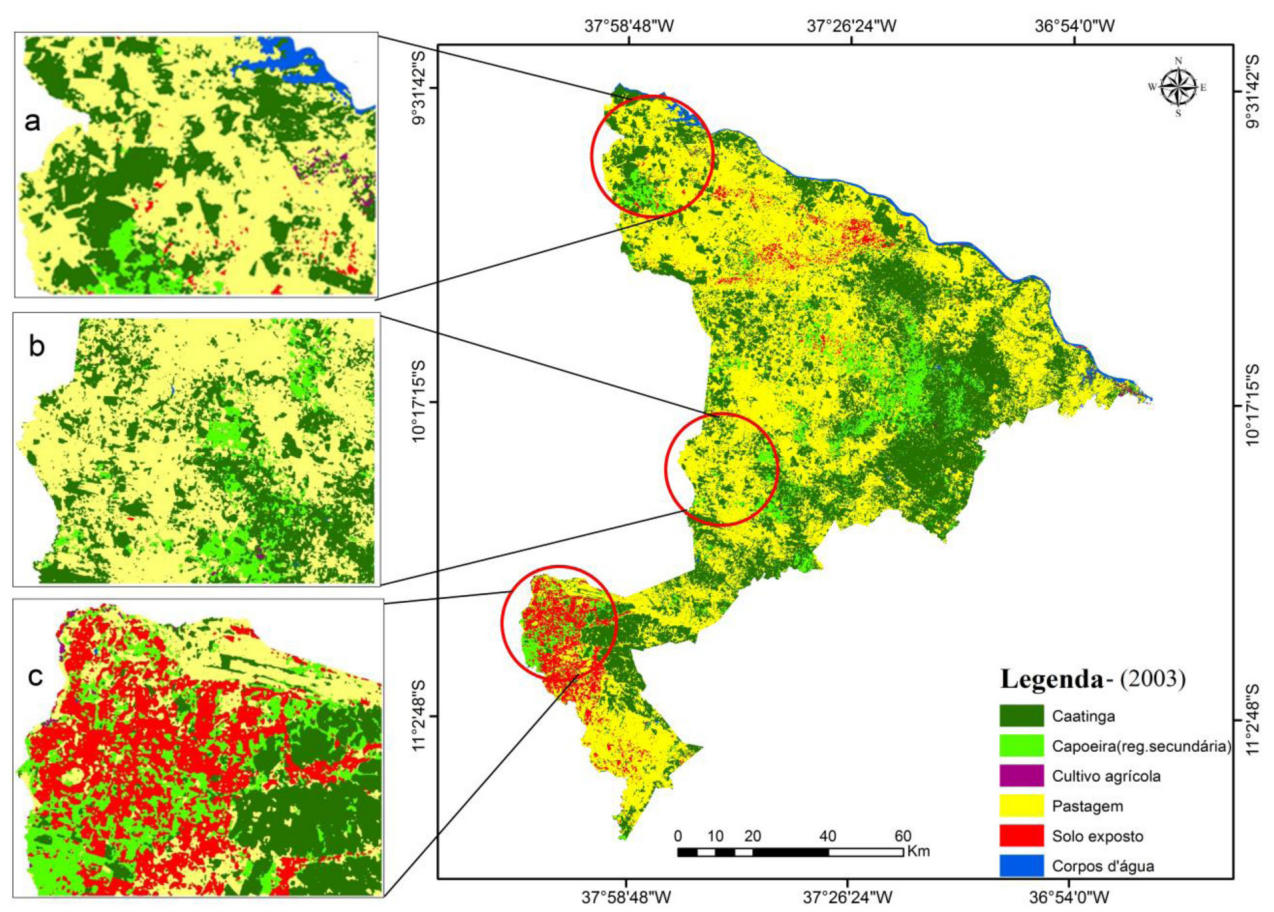

Figura 3. Mapa de uso e cobertura da terra da região semiárida de Sergipe no ano 2003; em em destaque, as regiões do Alto Sertão (a), Agreste Central (b) e Centro-Sul (c).

Figure 3. Land use/land cover map in the semiarid region of Sergipe the year 2003, and featured in the Hinterland (a) Central Wasteland (b) and Central South (c).

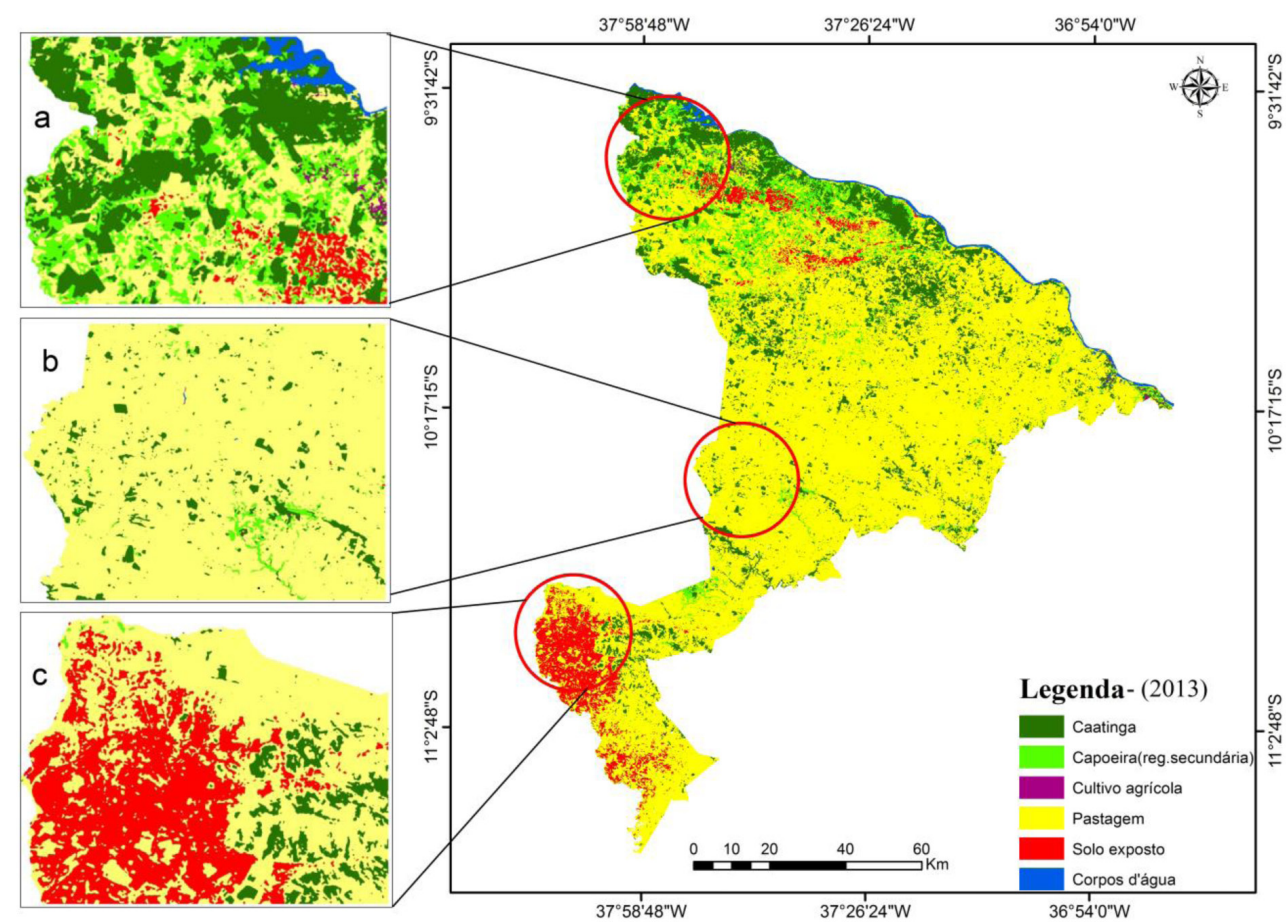

Figura 4. Mapa de uso e cobertura da terra da região semiárida de Sergipe no ano 2013; em em destaque, as regiões do Alto Sertão (a), Agreste Central (b) e Centro-Sul (c).

Figure 4. Land use/land cover map in the semiarid region of Sergipe the year 2013, and featured in the Hinterland (a) Central Wasteland (b) and Central South (c). 
campo, foi observado que essa região está inserida em uma área com presença frequente de cultivos agrícolas e assentamentos e próximo ao Rio São Francisco, o que favorece o processo de conversão de Caatinga em áreas de produção agropecuária.

Na região do Agreste Central do semiárido de Sergipe, observa-se que, mesmo em 1992, já existia um predomínio de pastagem e que, ao longo do tempo, houve um aumento dessa classe. Observa-se também que as áreas de Caatinga e regeneração natural foram substituídas por pastagem de 2003 a 2013 (Figuras 2b, 3b e 4b).

Em outros biomas, verifica-se ainda a substituição da vegetação nativa por áreas de pastagens. No cerrado do Mato Grosso, Gouveia et al. (2013), em um estudo de análise multitemporal, observaram que a classe pastagem foi a mais expressiva nos 27 anos analisados. Valle et al. (2012), em um diagnóstico de mudança do uso da terra entre 1978 e 2011 no Triângulo Mineiro, mostraram que a vegetação nativa reduziu sua área em $19,2 \%$, sendo substituída por agricultura e pastagem. Na região Centro-Sul da região semiárida de Sergipe (Figuras 2c, 3c e 4c), houve um aumento das áreas de regeneração natural e de solo exposto entre os anos de 1992 a 2003. Entre os anos de 2003 a 2013, observou-se uma diminuição da regeneração secundária, dando lugar à pastagem e ao solo exposto, além da conversão de Caatinga em pastagem. Em observações de campo, constatou-se que as áreas de solo exposto são antigas pastagens transformadas em áreas desertificadas por causa do superpastejo. Cheung et al. (2009) concluíram que a presença de pastagem afeta negativamente a regeneração secundária, devido à sua adaptação a solos com poucos nutrientes, ao rápido crescimento e ao maior acúmulo de biomassa vegetal.

Esses resultados também podem ser relacionados com os dados do Instituto Brasileiro de Geografia e Estatística - IBGE (2011), nos quais é possível notar que a supressão da vegetação nativa no Estado de Sergipe está ligada à expansão de pastagens de alto retorno econômico, as quais ocupam mais de $50 \%$ da área do território Centro-Sul.

$\mathrm{Na}$ Tabela 4 e na Figura 5, é possível visualizar a dinâmica da cobertura florestal nos períodos de estudo, ao se retratar a variação percentual em área de Caatinga preservada, de regeneração florestal e de desmatamento. Foi observado que a cobertura florestal na região semiárida encontra-se em cenário de decréscimo, visto que, nos 21 anos de avaliação, a Caatinga preservada e a regeneração apresentaram variações. Destaca-se a considerável diminuição da Caatinga, com 18,7\% entre os anos de 1992 e 2003, $10,5 \%$ entre 2003 e 2013 e $9,4 \%$ em todo o período de estudo (1992 a 2013).

Diante desse exposto, presume-se que está ocorrendo degradação nessa região, bem como a diminuição de regeneração florestal e um aumento do desmatamento. Esse fato é um retrato decorrente da falta de conscientização dos proprietários sobre a importância das florestas para o meio ambiente e a
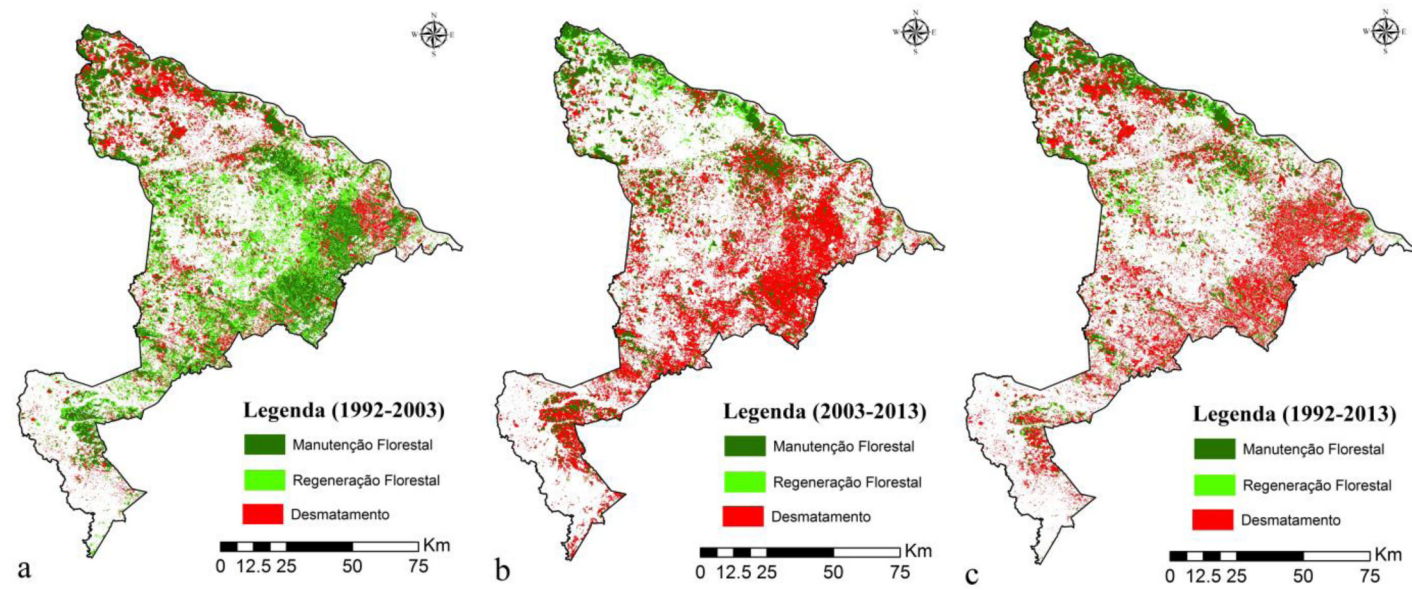

Figura 5. Mapas da dinâmica da cobertura florestal para os períodos de 1992 a 2003(a), 2003 a 2013 (b) e 1992 a 2013(c).

Figure 5. Maps of the dynamics of forest cover for the periods 1992-2003 (a); 2003-2013 (b) and 1992-2013 (c). 
Tabela 4. Quantificação da dinâmica de cobertura florestal e suas respectivas porcentagens entre os períodos de 1992-2003, 2003-2013 e 1992-2013 na região semiárida de Sergipe.

Table 4. Quantifying of the dynamics of forest cover and their respective percentages between the periods 1992-2003, 2003-2013 and 1992-2013 in the semiarid region - SE.

\begin{tabular}{rcccc}
\hline Períodos & Área & Caatinga preservada & Regeneração florestal & Desmatamento \\
\multirow{2}{*}{$1992-2003$} & $\left(\mathrm{Km}^{2}\right)$ & $2.090,8$ & $1.771,5$ & $1.554,2$ \\
& $\%^{*}$ & 18,7 & 15,9 & 13,9 \\
$2003-2013$ & $\left(\mathrm{Km}^{2}\right)$ & 1.176 & 421,6 & $2.986,8$ \\
& $\%^{*}$ & 10,5 & 3,8 & 26,7 \\
\multirow{2}{*}{$1992-2013$} & $\left(\mathrm{Km}^{2}\right)$ & $1.046,9$ & 465,1 & $2.645,4$ \\
\hline
\end{tabular}

*As porcentagens são em relação à área total da região de estudo $\left(10.729,2 \mathrm{Km}^{2}\right)$.

falta de fiscalização dos órgãos ambientais. Também de acordo com Silva et al. (2013), estudando o semiárido do município de Floresta, em Pernambuco, a diminuição da cobertura florestal entre 1987 e 2008 foi a principal consequência da interação entre clima, pressão antrópica por recursos florestais, necessidade de expansão urbana e atividades agropecuárias.

Silva et al. (2009), avaliando a dinâmica espaço-temporal da vegetação no semiárido de Pernambuco entre os anos de 1994, 1997 e 2001, verificaram que a vegetação característica da região diminuiu sua área, mostraram que as áreas analisadas encontram-se em processo de perda da vegetação, que pode levar ao processo de desertificação, e verificaram também que houve perda de vegetação entre os períodos limites do estudo.

A regeneração florestal, no primeiro período analisado de 1992 a 2003, apresentou um incremento de $15,9 \%$, o que contabiliza $1.771,5 \mathrm{Km}^{2}$ (Tabela 4 e Figura 5). Esse aumento, nesse primeiro período, pode ser explicado pelo fato de as áreas de pastagens terem sido abandonadas, o que favoreceu a regeneração.

Já no segundo período de 2003 a 2013, houve uma diminuição de 3,8\%, com uma redução de 421,6 km². Essa ocorrência explica-se por meio do aumento de pastagens para atender às indústrias de laticínios, com a necessidade de crescimento da produção e da disponibilidade de alimentos. No período de 1992 a 2013, a regeneração florestal apresentou um baixo incremento.

Silva et al. (2014), estudando a alteração da cobertura vegetal na sub-bacia do Rio Espinharas, no semiárido nordestino, no período de 2000 a 2010, encontraram os seguintes resultados: $80 \%$ da área se manteve inalterada; em 12,6\% da área ocorreu redução da cobertura vegetal devido às práticas de corte raso para obtenção de lenha para uso doméstico ou comercial e ao preparo da área para a agricultura; em $7,4 \%$ da área registrou-se regeneração, possivelmente favorecido pelo cultivo de pastagens irrigadas e não irrigadas em solos de aluvião.

O desmatamento, no período analisado de 1992 a 2003 , teve um aumento de $13,9 \%$, com uma redução da Caatinga e da regeneração florestal de $1.554,2 \mathrm{~km}^{2}$. Esse aumento no desmatamento pode estar relacionado à produção leiteira na região. No segundo período, entre 2003 e 2013, houve um grande aumento no desmatamento de $26,7 \%$, totalizando $2.986,8 \mathrm{~km}^{2}$, apresentando o dobro do desmatamento do período anterior. Considerando todo o período entre 1992 a 2013, o desmatamento apresentou um aumento expressivo (Tabela 4 e Figura 5).

Coelho et al. (2014), avaliando a dinâmica do uso do solo em uma bacia no semiárido nordestino no Estado de Pernambuco, observaram que os resultados entre as classes de uso passaram por uma grande transição, com aumento do desmatamento pela retirada da vegetação da Caatinga e substituição rápida e progressiva por áreas com pastagem e agricultura.

Na região semiárida da Paraíba, no município de Boa Vista, em um estudo sobre a evolução espaço temporal da cobertura vegetal, Sousa et al. (2008) observaram que o desmatamento está em extensões preocupantes, com manchas de solo exposto que se mostraram presentes em toda área, sendo que os solos continuam sendo usados pela pecuária extensiva, principalmente a caprina e a ovinocultura, atividades de maior potencial para o município por oferecer maior adaptabilidade às condições ambientais.

Resultados diferentes deste estudo foram encontrados em Santos et al. (2012), que, avaliando a evolução da 
cobertura florestal no bioma Mata Atlântica no município de Santa Maria de Jetibá, no Espírito Santo, observaram um incremento de $17 \%$ de cobertura florestal entre os anos de 1970 a 2008, superando o desmatamento.

\section{CONCLUSÕES}

A região semiárida de Sergipe sofreu intensos processos de antropização no período desta análise, principalmente entre os anos de 2003 a 2013. A vegetação da Caatinga foi a classe mais impactada, sendo a maior parte convertida em pastagens. O estudo da dinâmica da cobertura florestal evidenciou também a redução da regeneração florestal na região semiárida da Caatinga do Sergipe entre 2003 e 2013.

Tais resultados são preocupantes e requerem a tomada de decisão para a proteção do remanescente de vegetação nativa na região. Trata-se de ambientes muito degradados em que o pouco que resta de Caatinga e de outros tipos de vegetação nativa apresenta-se como extremamente relevantes para a manutenção do equilíbrio ecossistêmico. Tal destruição da vegetação nativa compromete ainda o potencial e a viabilidade atual e futura do manejo florestal na região deste estudo.

Deve-se ainda considerar que a pressão antrópica, especialmente a pecuária, é um fator preocupante para os próximos anos. Essa atividade apresentou a maior expansão territorial no período de estudo, e, por isso, é esperado a manutenção dessa tendência de crescimento para os próximos anos. Tal fato deve ser seriamente considerado para redução dos impactos em âmbito regional e para ampliação dos benefícios socioambientais das comunidades locais, assim como para sua contribuição na esfera global em reduzir as emissões de gases do efeito estufa que levam às mudanças climáticas no planeta.

\section{AGRADECIMENTOS}

À Coordenação de Aperfeiçoamento de Pessoal de Nível Superior (Capes), pela bolsa concedida, e à Universidade de Brasília (UnB), pelo mestrado em Ciências Florestais.

\section{STATUS DA SUBMISSÃO}

Recebido: 21 nov., 2014

Aceito: 16 maio, 2015
AUTOR(ES) PARA CORRESPONDÊNCIA

\section{Márcia Rodrigues de Moura Fernandes}

Departamento de Engenharia Florestal,

Universidade de Brasília - UnB,

Campus Universitário Darcy Ribeiro, s/n, Asa

Norte, CEP 70904-970, Brasília, DF, Brasil

e-mail: marciarmfe@gmail.com

\section{REFERENNCIAS}

Alves JJA. Geoecologia da Caatinga no semiárido do Nordeste brasileiro. Climatologia e Estudos da Paisagem 2007; 2(1): 58-71.

Araújo DR, Silva PCM, Dias NS, Lira DLC. Estudo da área de preservação permanente do rio Mossoró no sítio urbano de Mossoró-RN por meio de técnicas de geoprocessamento. Revista Caatinga 2012; 25(2): 177-183.

Barbosa IS, Andrade LA, Almeida JAP. Evolução da cobertura vegetal e uso agrícola do solo no município de Lagoa Seca, PB. Revista Brasileira de Engenharia Agrícola e Ambiental 2009; 13(5): 614-622. http://dx.doi.org/10.1590/ S1415-43662009000500015.

Brasileiro RS. Alternativas de desenvolvimento sustentável no semiárido nordestino: da degradação à conservação. Scientia Plena 2009; 5(5): 1-12.

Cheung KC, Marques MCM, Liebsch D. Relação entre a presença de vegetação herbácea e a regeneração natural de espécies lenhosas em pastagem abandonadas na floresta ombrófila densa do sul do Brasil. Acta Botanica Brasílica 2009; 23(4): 1048-1056. http://dx.doi.org/10.1590/S010233062009000400015

Coelho VHR, Montenegro SMGL, Almeida CN, Lima ERV, Ribeiro A No, Moura GSS. Dinâmica do uso e ocupação do solo em uma bacia hidrográfica do semiárido brasileiro. Revista Brasileira de Engenharia Agrícola e Ambiental 2014; 18(1): 64-72. http://dx.doi.org/10.1590/ S1415-43662014000100009.

Companhia de Desenvolvimento dos Vales do São Francisco e do Parnaíba - CODEVASF [online]. 2010. [citado 2014 Abr. 6]. Disponível em: http://www.codevasf.gov.br.

Cunha JEBL, Rufino IAA, Silva BB, Chaves IB. Dinâmica da cobertura vegetal para a Bacia de São João do Rio do Peixe, $\mathrm{PB}$, utilizando-se sensoriamento remoto. Revista Brasileira de Engenharia Agrícola e Ambiental 2012; 16(5): 539-548. http://dx.doi.org/10.1590/S1415-43662012000500010.

Feitosa HCP, Andrade KS, Barbosa MP, Ribeiro GN Avaliação do processo de degradação da cobertura vegetal em Serra Branca e Coxixola - PB. Revista Verde de Agroecologia e Desenvolvimento Sustentável 2010; 5(1): 1-7.

Gouveia RGL, Galvanin EAS, Neves SMAS. Aplicação do índice de transformação antrópica na análise multitemporal 
da bacia do córrego do bezerro vermelho em Tangará da Serra-MT. Revista Árvore 2013; 37(6): 1045-1054. http:// dx.doi.org/10.1590/S0100-67622013000600006.

Instituto Brasileiro de Geografia e Estatística - IBGE. Área territorial oficial [online]. 2010. [citado 2014 Abr. 20]. Disponível em: http://www.ibge.gov.br/home/geociencias/ cartografia/default_territ_area.shtm.

Instituto Brasileiro de Geografia e Estatística - IBGE. Projeto levantamento e classificação do uso da terra [online]. Rio de Janeiro; 2011. [citado 2014 Jun. 19]. Disponível em: ftp://geoftp.ibge.gov.br/documentos/recursos_naturais/ manuais_tecnicos/usoterra_se.pdf.

Landis JR, Koch GG. The measurement of observer agreement for categorical data. Biometrics 1977; 33(1): 159-174. http://dx.doi.org/10.2307/2529310. PMid:843571.

Lillesand TM, Kiefer RW. Remote sensing and image interpretation. 2. ed. Chichester: John Willey \& Sons; 1994.

Maia GN. Caatinga: árvores e arbustos e suas utilidades. São Paulo: Leitura \& Arte; 2004.

Nogueira FRB, Simões SVD. Uma abordagem sistêmica para a agropecuária e a dinâmica evolutiva dos sistemas de produção no nordeste semiárido. Revista Caatinga 2009; 22(2): 1-6.

Oliveira AG, Oliveira VS, Santos GRA, Ferreira ACD, Santos GS, Lima EPT et al. Diagnóstico socioeconômico da produção leiteira em três assentamentos de reforma agrária no semiárido do Estado de Sergipe. Semina: Ciências Agrárias 2013; 34(4): 1869-1878.

Prado RB, Novo EMLM, Pereira MN. Avaliação da dinâmica do uso e cobertura da terra na bacia hidrográfica de contribuição para o reservatório de Barra Bonita SP. Revista Brasileira de Cartografia 2007; 59(2): 127-135.

Projeto de Conservação e Utilização Sustentável da Diversidade Biológica Brasileira - PROBIO. Subprojeto: levantamento da cobertura vegetal e do uso do solo do bioma caatinga [online]. 2007. [citado 2014 Jun. 20]. Disponível em: http://mapas.mma.gov.br/geodados/brasil/vegetacao/ vegetacao2002/caatinga/documentos/relatorio_final.pdf.

Santos AR, Almeida HC Jr, Eugenio FC. Evolução da Cobertura Florestal no Município de Santa Maria de Jetibá - ES. Revista Floresta e Ambiente 2012; 19(3): 296-307. http://dx.doi.org/10.4322/floram.2012.035.

Sergipe. Diagnóstico florestal de Sergipe. 1. ed. Aracajú: Secretaria de Estado do Meio Ambiente e dos Recursos Hídricos; 2014.

Serviço Florestal Brasileiro - SFB. Florestas do Brasil em resumo: dados de 2007 a 2012. Brasília: SFB; 2013.

Silva APN, Moura GBA, Giongo PR, Silva A. Dinâmica espaço-temporal da vegetação no semiárido de Pernambuco. Revista Caatinga 2009; 22(4): 195-205.

Silva EA, Ferreira RLC, Silva JAA, Sá IB, Duarte SMA. Dinâmica do uso e cobertura da terra do município de Floresta - PE. Floresta 2013; 43(4): 611-620. http://dx.doi. org/10.5380/rf.v43i4.27931.

Silva RMP, Lima JR, Mendonça IFC. Alteração da cobertura vegetal na Sub-Bacia do Rio Espinharas de 2000 a 2010. Revista Brasileira de Engenharia Agrícola e Ambiental 2014; 18(2): 202-209. http://dx.doi.org/10.1590/S141543662014000200011 .

Silva VA, Moreau MS, Moreau AMSS, Rego NAC. Uso da terra e perda de solo na Bacia Hidrográfica do Rio Colônia, Bahia. Revista Brasileira de Engenharia Agrícola e Ambiental 2011; 15(3):310-315. http://dx.doi.org/10.1590/ S1415-43662011000300013.

Sousa RF, Barbosa MP, Sousa SP Jr, Nery AR, Lima AN. Estudo da evolução espaço-temporal da cobertura vegetal do município de Boa Vista-PB, utilizando geoprocessamento. Revista Caatinga 2008; 21(3): 22-30.

Valle RF Jr, Siqueira HE, Guidolini JF, Abdala VL, Machado MF. Diagnóstico de mudanças e persistência de ocupação do solo entre 1978 e 2011 no IFTM-CAMPUS UBERABA, utilizando o "Land Change Modeler (LCM)". Enciclopédia Biosfera 2012; 8(15): 672-681. 